\title{
Neuroscience of Exercise and Virtual Reality Applications
}

\author{
Renato Sobral Monteiro-Junior \\ Doctoral Program in Neuroscience, Federal Fluminense University \\ Researcher of the Neuroscience Laboratory of Exercise (LaNEx) UERJ/UFRJ, \\ Professor and Researcher of State University of Montes Claros, MG, Brazil.
}

Physical exercise has an important role in general health and well-being. In the last 30 years, the scientific community began research in the field of neuroscience and exercise [1]. Up to date, around 1,753 studies (average 58/year) related to this subject were published [2]. The neuroscience of exercise addresses the effects of exercise on the brain in different populations (older adults, athletes, patients with neurological disorders and children). Although this subject is a relatively new research area, much evidence has already shown the benefits of exercise on mental health [3]. Some of the neurobiological mechanisms of exercise are related to neurogenesis, angiogenesis and synaptogenesis, among others [4], which are hypothesized as being beneficial for the treatment of Parkinson's disease, Alzheimer's disease, Major Depression, and cognitive impairment [3-5].

Recently, new strategies added to physical exercise have been used in diverse rehabilitation fields, such as robotic, biofeedback, cortical stimulation and virtual reality, among others [6-9]. Specifically related to virtual reality and exercise in rehabilitation settings, it is important to highlight the benefits, feasibility, safety, and availability of some commercial devices. These equipments are inexpensive, easily used by healthy professionals and can be applied in several fields of rehabilitation [10,11]. The main benefits associated to physical exercise coupled to virtual reality are the improvement of physical performance and cognitive functions of patients with neurological disorders and older adults. These effects can be explained by neuroplasticity.

During exercise coupled to virtual reality, the individual is immersed in a virtual environment, which causes the "presence". Immersion is the amount of sensorial flow of information that stimulates many sensorial systems and, consequently, simulates a virtual environment. This leads to the production of physiological responses and feelings related to this environment. Therefore, the product of immersion is known as presence (sensation of staying in a given location) [12]. These phenomena influence brain behavior and can alter motor and cognitive responses. You et al [13] demonstrated a cortical reorganization in stroke survivors after a rehabilitation program of exercise coupled to virtual reality. Extraordinarily, the ipsilateral regions of the injured brain became more active during isometric knee extension. These results were associated with motor improvement. In this context, Maillot et al [14] demonstrated improvement of cognitive function and motor performance of healthy older adults after physical exercise training with exergames (exercise and active video games). Thus, this kind of exercise training appears to be an effective intervention from brain to body.

Immersion in a virtual environment requires the activation of important brain regions related to movement and cognition. This activation is critical for navigation abilities. Maguire et al [15] showed that the prefrontal cortex, caudate nucleus, hippocampus, and parietal cortex increased their activation during navigation activities. These results were associated to decision making, planning, velocity of displacement, episodic memory, and accuracy during navigation. Therefore, it is possible that motor stimulation in conjunction with virtual navigation can produce higher power clinical results. This speculation is based on two hypotheses: 1. Physical exercise stimulates the release of peripheral trophic factors, which can cross the blood brain barrier; and 2. Virtual reality can stimulate cognitive brain regions, increasing the release of central trophic factors. Both stimulations by dual task could improve brain functioning and clinical responses [16].

Although virtual reality and exercise applications in neuroscience require future investigations, studies have been important in demonstrating clinical benefits for different populations. The use of this kind of intervention is encouraged in neuroscience fields, although caution is needed since adverse effects related to excessive exposure to virtual reality is not yet well understood. 


\section{REFERENCES}

[1] Enoka RM, Stuart DG: The contribution of neuroscience to exercise studies. Fed Proc 1985;44:2279-2285.

[2] PubMed: Pubmed search http://www.Ncbi.Nlm.Nih.Gov/pubmed/ ?Term=\%22neuroscience\% $22+$ and $+\% 22$ exercise $\% 22$. Access in october $14<\mathrm{p}$ class="Msolistparagraph" Style="Textalign:Justify;text-indent:-18.0pt; mso-list:L0 level1 lfo1">, 2015,

[3] Deslandes A, Moraes H, Ferreira C, Veiga H, Silveira H, Mouta R, Pompeu FA, Coutinho ES, Laks J: Exercise and mental health: Many reasons to move. Neuropsychobiology 2009;59:191198.

[4] Matta Mello Portugal E, Cevada T, Sobral Monteiro-Junior R, Teixeira Guimarães T, da Cruz Rubini E, Lattari E, Blois C, Camaz Deslandes A: Neuroscience of exercise: From neurobiology mechanisms to mental health. Neuropsychobiology 2013;68:1-14.

[5] Monteiro-Junior RS, Souza CP, Lattari E, Rocha NBF, Machado SM, Silva EB: Wiiworkouts on chronic pain, physical capabilities and mood of older women: A randomized controlled double blind trial, 2015 in Press,

[6] O'Connor RJ, Jackson A, Makower SG, Cozens A, Levesley M: A proof of concept study investigating the feasibility of combining ipam robot assisted rehabilitation with functional electrical stimulation to deliver whole arm exercise in stroke survivors. J Med Eng Technol 2014;39:411-418.

[7] Pagé I, Marchand AA, Nougarou F, O'Shaughnessy J, Descarreaux M: Neuromechanical responses after biofeedback training in participants with chronic low back pain: An experimental cohort study. J Manipulative Physiol Ther 2015;38:449-457.

[8] Chang MC, Do KH, Chun MH: Prediction of lower limb motor outcomes based on transcranial magnetic stimulation findings in patients with an infarct of the anterior cerebral artery. Somatosens Mot Res 2015:1-5.

[9] McNulty PA, Thompson-Butel AG, Faux SG, Lin G, Katrak PH, Harris LR, Shiner CT: The efficacy of wii-based movement therapy for upper limb rehabilitation in the chronic poststroke period: A randomized controlled trial. Int J Stroke 2015

[10] Monteiro Junior RS, Silva EB: Effectiveness of the virtual rehabilitation on body balance and motor abilities ofindividuals with neuromotor impairment: A systematic review. Brazilian Journal of Physical Activity and Health 2012;17:224-230.

[11] RS M-J, CP S, E L, S M, EB S: Wii-workouts on chronic pain, physical capabilities and mood of older women. A randomized controlled double blind trial. CNS \& Neurological Disorders - Drug Targets 2015

[12] Bohil CJ, Alicea B, Biocca FA: Virtual reality in neuroscience research and therapy. Nat Rev Neurosci 2011;12:752-762.

[13] You SH, Jang SH, Kim YH, Hallett M, Ahn SH, Kwon YH, Kim JH, Lee MY: Virtual realityinduced cortical reorganization and associated locomotor recovery in chronic stroke: An experimenter-blind randomized study. Stroke 2005;36:1166-1171.

[14] Maillot P, Perrot A, Hartley A: Effects of interactive physical-activity video-game training on physical and cognitive function in older adults. Psychol Aging 2012;27:589-600.

[15] Maguire EA, Burgess N, Donnett JG, Frackowiak RS, Frith CD, O'Keefe J: Knowing where and getting there: A human navigation network. Science 1998;280:921-924.

[16] Monteiro-Junior R, Vaghetti C, Laks J, Nascimento O, Deslandes A: Exergames: neuroplastic hypothesis about cognitive improvement and biological effects on physical function of institutionalized older persons. Neural Regeneration Research 2015;Accepted, Ahead of print 